\title{
Polycyclic aromatic hydrocarbons in urban and rural residential soils, levels, composition profiles, source identification and health risk \& hazard
}

\author{
Bhupander Kumar $^{1}$ (D) $\cdot$ Virendra Kumar Verma $^{1} \cdot$ Disha Joshi $^{2,3} \cdot$ Sanjay Kumar ${ }^{1} \cdot$ Prashant Gargava $^{1}$
}

Received: 7 August 2020 / Accepted: 27 October 2020 / Published online: 18 November 2020

(c) Springer Nature Switzerland AG 2020

\begin{abstract}
The presence of PAHs in soil and the close proximity of soils to humans may lead to human exposure through various pathways. Therefore, levels of priority sixteen PAHs in soils were measured for human and environmental health risk assessments. No recent study on human and environmental health effects due to PAHs in soils is available for Delhi. The levels of total PAHs in soils ranged between $213-851 \mu \mathrm{g} \mathrm{kg}^{-1}$ with the mean of $550 \pm 55 \mathrm{\mu g} \mathrm{kg}^{-1}$, which was comparatively lower in rural area. Seven carcinogenic PAHs (7CPAHs) accounted for $28.6 \%$ of $\Sigma 16$ PAHs. However, benzo(a)pyrene toxicity equivalency $\left(\mathrm{BaP}_{\mathrm{TE}}\right)$ of $7 \mathrm{CPAHs}$ accounted for $98.2 \%$ to $\Sigma \mathrm{BaP}_{\mathrm{TE}}$. Lifetime average daily dose (LADD) of PAHs through soil for human adults and children was $9.43 \times 10^{-8} \mathrm{mg} \mathrm{kg}^{-1} \mathrm{~d}^{-1}$ and $3.53 \times 10^{-7} \mathrm{mg} \mathrm{kg}^{-1} \mathrm{~d}^{-1}$, respectively. The estimated incremental lifetime cancer risk (ILCR) for children $\left(4.80 \times 10^{-5}\right)$ was comparatively higher than adults $\left(1.29 \times 10^{-5}\right)$. The index of additive cancer risk (IACR), potential threat to potable groundwater water quality from leaching of carcinogenic PAHs from soil were also estimated and presented. The observed levels of PAHs in soils and their human health risk and environmental health hazard at different locations were assessed using recommended guidelines.
\end{abstract}

Keywords PAHs $\cdot$ Soil $\cdot$ Cancer risk $\cdot$ IACR

\section{Introduction}

Polycyclic aromatic hydrocarbons (PAHs), a group of organic compounds containing 2 or more benzene rings are released to the environment from petroleum products (petrogenic sources) and from various anthropogenic activities. Anthropogenic sources of PAHs include incomplete combustion of coal, petroleum products and biomass (pyrogenic sources). PAHs exert genotoxic effects with induced mutations through formation of
DNA-PAH adducts and cause to developing carcinogenesis [1]. Among several PAHs, 16 compounds namely naphthalene (NPT), acenaphthylene (ACY), acenaphthene (ANE), fluorine (FLE), phenanthrene (PHE), anthracene (ANT), fluoranthene (FLT), pyrene (PYR), benzo(a) anthracene $(\mathrm{BaA})$, chrysene $(\mathrm{CHR})$, benzo(b)fluoranthene $(B b F)$, benzo(k)fluoranthene (BkF), benzo(a)pyrene $(\mathrm{BaP})$, dibenzo(a,h)anthracene (DBA), benzo $(g, h, i)$ perylene (BghiP) and indeno (1,2,3-cd)pyrene (IndP) are classified and listed as the priority pollutants by

\section{Electronic supplementary material The online version of this article (https://doi.org/10.1007/s42452-020-03769-w) contains} supplementary material, which is available to authorised users.

Bhupander Kumar, bhupandercpcb@gmail.com | ${ }^{1}$ Central Pollution Control Board, East Arjun Nagar, Delhi 110032 , India. ${ }^{2}$ University School of Chemical Technology, GGS Indraprastha University, Dwarka, Delhi 110078, India. ${ }^{3}$ Department of Civil Engineering, IIT Delhi, Hauz Khas, Delhi 110016, India. 
USEPA [2] and European Community [3]. Based on the carcinogenicity, USEPA's carcinogenicity risk assessment verification endeavor work group [1] and WHO's the International Agency for Research on Cancer (IARC) [4] classified 16 PAHs into different groups. BaP has sufficient evidence of carcinogenicity in human, and classified as human carcinogen (group I). DBA with limited evidence of carcinogenicity in human and sufficient evidence of carcinogenicity in experimental animals, classified as probable carcinogens (group 2A). BaA, NPT, CHR, $\mathrm{BbF}, \mathrm{BkF}$, and IndP classified as possible carcinogens (group 2B), since inadequate evidence of carcinogenicity in human and limited evidence of carcinogenicity in experimental animals [1, 4].

PAHs are often transported over long distances through the atmosphere and partitioned into particulate and gaseous phase. They are ubiquitously distributed in various environmental compartments including air, water bodies, soil and vegetation [1]. Soils might be act as the source and sink for many organic pollutants including PAHs, and could play important role in the fate and distribution of PAHs in the environment. Industrial activities and vehicles are main sources of PAHs in urban soils $[1,5]$. Worldwide, several researchers reported health risk to humans through PAHs with in the soil [6-13].

In India, some studies have been carried out on PAHs associated risk for humans. Among them, few were on health impact due to PAHs through soils [14-19]. But, no recent report on humans and environmental health effects due to PAHs in soils is available for Delhi. However, PAHs were measured and reported for various soils including agricultural soils (range, $830-3880 \mu \mathrm{g} \mathrm{kg}^{-1}$ ) [20]), industrial soil $\left(11,460 \pm 8390 \mathrm{~g} \mathrm{~kg}^{-1}\right)$, roadside soil $\left(6960 \pm 4820 \mu \mathrm{g} \mathrm{kg}^{-1}\right)$, residential soil $\left(2120 \pm 1120 \mathrm{~g} \mathrm{~kg}^{-1}\right)$ [21], and mixed landuse soils (511-2241 $\mathrm{gg} \mathrm{kg}^{-1}$ ) [22] from Delhi. This study was focused on the amount and composition profiles of priority sixteen PAHs in soils, their possible sources, toxicity and health risk in urban and rural areas of Delhi.

\section{Materials and methods}

\subsection{Solvents, chemicals and standards}

Solvents \& chemicals, HPLC grade and analytical grade, respectively (Fisher Scientific, India), were utilized in sample processing and analysis. Activated silica (100-200 mesh) (Sigma-Aldrich, USA) was utilized in column chromatography for extract clean-up. Working standard solutions with suitable concentrations of $\mathrm{PAH}$ compounds were prepared with serial dilutions of stock solutions of individual standard solutions of sixteen PAHs including NPT (naphthalene), ANY (acenaphthylene), ANE (acenaphthene), PHE (phenanthrene), ANT (anthracene), FLT (fluoranthene), PYR (pyrene), BaP (benzo(a)pyrene), BghiP (benzo(g,h,i)perylene), FLE (fluorene), $\mathrm{BaA}$ (benzo(a) anthracene), CHR (chrysene), BbF (benzo(b)fluoranthene), BkF (benzo(k)fluoranthene), DBA (dibenzo(a,h)anthracene) and IndP (indeno(1,2,3-cd)pyrene) (Supelco, Sigma-Aldrich, USA). Mixture of $16 \mathrm{PAH}$ compounds was used for calibration and internal quality control analysis.

\subsection{Study area and sampling}

Delhi $\left(28.38 \mathrm{~N}\right.$ and $\left.77.13^{\circ} \mathrm{E}\right)$ is the capital of India with $1483 \mathrm{~km}^{2}$ area and 16.78 million of total population. The climate of Delhi is tropical semi-arid. The atmospheric temperature varied between 4 and $5{ }^{\circ} \mathrm{C}$ and $40-45^{\circ} \mathrm{C}$ during winter and summer season, respectively. Generally, winds are north-western and south-eastern during monsoon season. The region received $\sim 714 \mathrm{~mm}$ annual average rainfall mostly in monsoon season. The transportation is predominantly road based and therefore the total numbers of registered vehicles in Delhi are 9.7 million [23]. In terms of particulate, Delhi was listed among the foremost polluted cities. The amount of particulate in Delhi air varied seasonally and greatly influenced by environmental conditions [24]. The main sources of air pollution in Delhi are reported because of local sources, including long range atmospheric transport (LRAT) of pollutants [25].

The selected sampling locations, Sirifort (S-1), Dilshad Garden (S-2), Janakpuri (S-3) and Pitampura (S-5) were in urban residential districts, while the location of Bakhtawarpur (S-4) is in rural residential area of Delhi. Sampling locations S-1, S-2, S-3 and S-5 are located in South Delhi, West Delhi, East Delhi and North Delhi respectively. While, the location S-4 is in rural district of North Delhi in. In 2016, during summer season, total forty soil samples were collected from different points of selected sampling locations (Fig. 1, Table S1). 3-5 sampling points were within a 100-200 m radius of every sampling location that was selected for soil sampling. Three $\sim 500 \mathrm{~g}$ of sub-surface (0-20 cm depth) soil sample was collected from each selected point from different locations. After manual removal of unwanted materials, the collected subsample at each points of every location are combined and mixed thoroughly to make sure a representative sample of that point of an equivalent location. An 


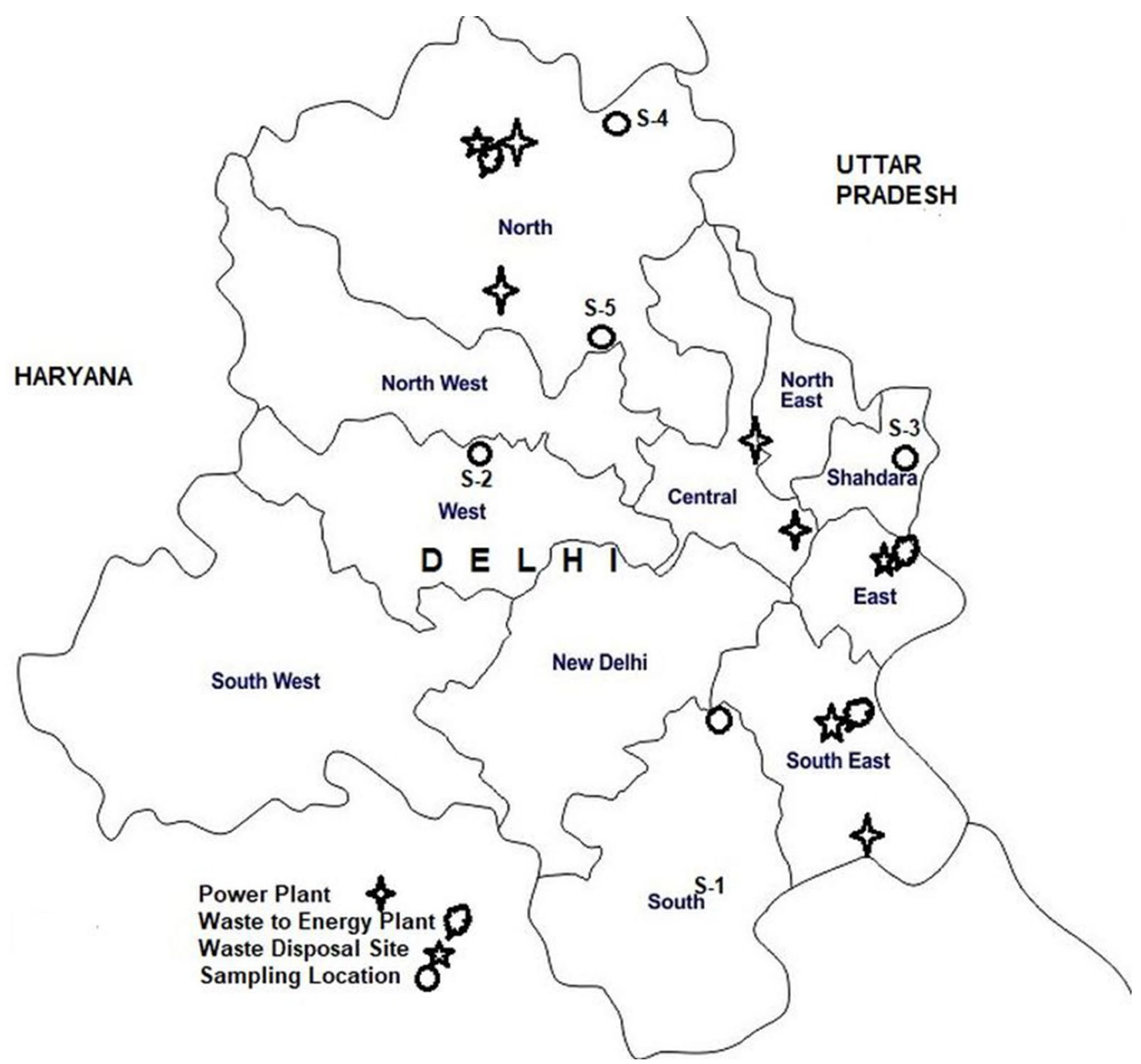

Fig. 1 Map showing sampling locations in study area in Delhi, India

aliquot of mixed soil ( $200 \mathrm{~g})$ in duplicates was collected in wide mouth amber glass containers, and transported to the laboratory.

\subsection{Analysis and internal quality control}

The air dried homogenized samples of $1 \mathrm{~mm}$ size $(\sim 20 \mathrm{~g})$ were extracted with acetone-hexane $(1: 1 \mathrm{v} / \mathrm{v})$ on ultrasonic bath (USEPA Method 3550C). After sonication, solvent extracted layer was passed through anhydrous sodium sulphate on Whatman 41 paper, and the process was repeated for 2 more times. The pooled extract was concentrated to close $2 \mathrm{~mL}$ under reduced pressure at $40^{\circ} \mathrm{C}$ using vacuum rotary evaporator (Eyela, Tokyo, Japan). Column chromatography with activated silica was followed for clean-up following the USEPA Method 3630C. Individual PAH compounds were quantified following method detailed elsewhere [26].

Strict analytical quality control analysis was followed with inclusion of multi-level calibration, calibration 
verification, method blanks analysis and analysis in duplicates. Five level calibration curves with required linearity $\left(r^{2}, 0.999\right)$ and accurate retention time of each standard PAHs were used for identification of the individual PAH compounds in samples. Measurement of every sample extract was taken in duplicate and therefore the average of duplicate analyses was utilized in calculations. Accuracy of method performance was checked by recovery study. Recovery was carried out by analysis of fortified samples with the addition of known quantity of 1-fluoronaphthalene (surrogate standard) and individual 16PAH standards. The recoveries of added 16 PAHs were between $82 \%-109 \%( \pm 2-12 \%)$, while recovery of surrogate standard was $94 \%$. Method detection limits (DLs) were estimated at signal to noise ratio $>3: 1(s / n>3)$ by processing and analysis of eight replicates of a sample. Estimated DLs for sixteen PAH

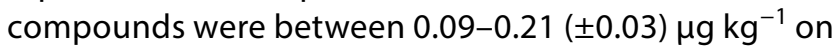
dry weight basis.

\subsection{Toxicity potential and health risk assessment}

Previously defined toxicity equivalency factors (TEFs) [27] were wont to estimate the $\mathrm{BaP}_{\mathrm{TE}}$ of the remaining $\mathrm{PAH}$ s relative to $\mathrm{BaP}$ (Table S4). The toxicity equivalent (based on carcinogenicity) of every individual PAH was obtained by multiplying its concentration with the acceptable TEF.

As recommended by Canadian soil quality guidelines, BaP Total Potency Equivalents (BaP TPE) and IACR were estimated [28]. BaP TPE is the sum of the estimated cancer potency relative to $\mathrm{BaP}$ for all potentially carcinogenic PAHs (BaA, BaP, BbF, BkF, BghiP, CHR, DBA, IndP) [28].

Human exposure to PAHs may occur through inhalation, ingestion and dermal contact. During this study, human health risk estimation was based on consideration of ingestion pathway of PAHs through soil. The LADD and ILCR were estimated using input parameters (Table S2) with following equations $[5,29]$ :

$\operatorname{LADD}\left(\mathrm{mg} \mathrm{kg}^{-1} \mathrm{~d}^{-1}\right)=(\mathrm{C} \times \mathrm{IR} \times \mathrm{F} \times \mathrm{EF} \times \mathrm{ED}) /(\mathrm{BW} \times \mathrm{AT})$

\section{Cancer Risk $=\mathrm{LADD} \times \mathrm{CSF}$}

Non-carcinogenic effects of PAHs as environmental hazard were assessed by comparison of observed concentrations with recommended soil quality guidelines for mammals and residential/park landuse [28, 31].

\subsection{Statistical analyses}

Microsoft Excel was used for the data processing, graphics and Pearson's correlation analysis. The Pearson correlation analysis was wont to identify the sources of PAHs in soils. This statistical approach is predicted on the coefficient of correlation between the concentrations of the individual $\mathrm{PAH}$ can give a thought, whether or not they originate from an equivalent source or not. Results were considered statistically significant if the $p$-value was $<0.01$. Each PAH was evaluated for values below detection limit before inclusion within the processing. Missing data points resulting from limit of detection weren't considered in calculations. Nemerow composite index ( $P$ value) was calculated for the assessment of environmental quality of soil due to PAHs [32].

\section{Results and discussions}

\subsection{Levels of PAHs}

The average concentration of total PAHs was comparatively higher in urban soils $\left(550 \pm 55 \mu \mathrm{g} \mathrm{kg}^{-1}\right)$ than rural soils location ( $224 \pm 7.1 \mu \mathrm{g} \mathrm{kg}^{-1}$ ) (Fig. 2). The spatial distribution of total PAHs at different locations was with increasing order at S-3 $>\mathrm{S}-5>\mathrm{S}-2>\mathrm{S}-1>\mathrm{S}-4$. Levels of $\mathrm{PAHs}$ in soils from rural location (S-4) were comparatively less than the opposite locations (urban). Urban soils show dominance of FLT, PYR, NPT, PHE, and BghiP, followed by ANY, ANE, ANT, BaP and DBA. Their contribution was accounted for $15.1 \%, 12.6 \%, 8.5 \%, 7.5 \%, 7.1 \%$, $6.1 \%, 5.6 \%, 5.1 \%, 5.1 \%$ and $5.0 \%$, respectively to $\Sigma \mathrm{PAHs}$.

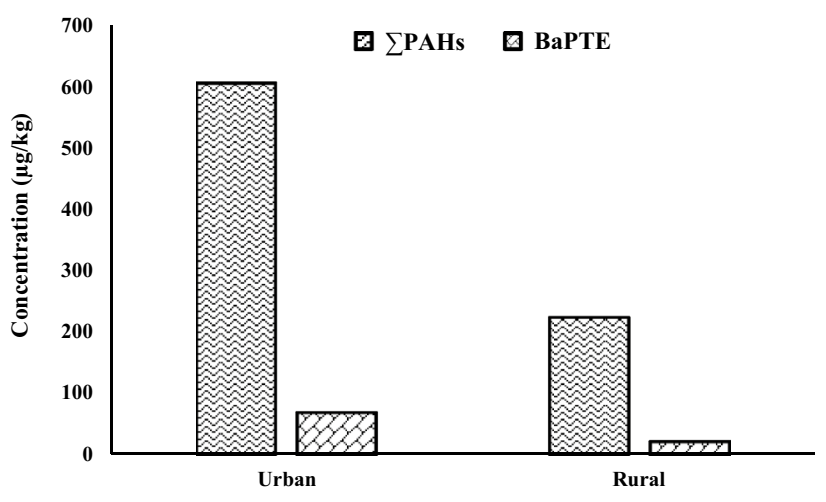

Fig. 2 Concentrations of $\sum \mathrm{PAH}$ s and $\sum \mathrm{BaP}_{\mathrm{TE}}(\mu \mathrm{g} / \mathrm{kg})$ in soil 
However, ANE, PHE, NPT, and ANT were the dominant PAHs in rural soils, followed by ANY, BaA, BbF, CHR, PYR and FLE. The contribution of ANE, PHE, NPT, ANT, ANY, and $\mathrm{BaA}$ in rural soils accounted for $9.8 \%, 8.6 \%, 8.3 \%$, $7.5 \%, 6.9 \%$, and $6.6 \%$, respectively to $\Sigma \mathrm{PAHs}$ (Table $\mathrm{S} 3$ ). The observed composition profiles of PAHs suggested diesel-powered vehicles emission and biomass combustions as major sources of PAHs [33]. Similar sources of $\mathrm{PAHs}$ are reported for different environmental matrices in Delhi $[22,24,25]$. However, with the limitations of sampling during summer season, these observations may be varied with different seasons.

The observed concentration of PAHs was compared with similar recent studies round the world including India. It was found that the concentrations are comparable with concentrations reported for Dibrugarh

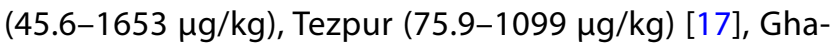
ziabad $(574 \pm 304 \mu \mathrm{g} / \mathrm{kg})[18]$, and Gwalior $(481 \pm 92 \mu \mathrm{g} /$ $\mathrm{kg}$ ) [19] in India. But, lower concentration was reported for Itanagar (15.8-98.9 $\mu \mathrm{g} / \mathrm{kg}$ ) [17]. However, elevated concentrations are reported for a few Indian cities, including Dhanbad (3488 $\mu \mathrm{g} / \mathrm{kg})$ [14], Guwahati $(50.5-4686 \mu \mathrm{g} /$ $\mathrm{kg}$ [15], and north-eastern region $(10,945 \mu \mathrm{g} / \mathrm{kg})$ [16]. Recently, elevated concentrations of seven PAHs ( $\Sigma$ of NPT, FLE, PHE, ANT, FLT, PYR \& BaP) (956-2714 $\left.\mu \mathrm{g} \mathrm{kg}^{-1}\right)$ were reported in soils from power station area, interstate bus terminals and heavy traffic intersections in Delhi [34]. On comparison with similar studies from other countries, the observed concentrations were much less than concentrations reported for Beijing $(736 \pm 894 \mu \mathrm{g} / \mathrm{kg}$ ) [35], Orlando $(3227 \pm 4676 \mu \mathrm{g} / \mathrm{kg})$ and Thampa $(4562 \pm 10,031 \mu \mathrm{g} /$ kg) Florida in USA [36], Shengli $(2160 \mu \mathrm{g} / \mathrm{kg})$ [37], Xian

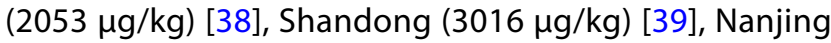
$(980 \mu \mathrm{g} / \mathrm{kg})$ [40], Ulsan $(810 \mu \mathrm{g} / \mathrm{kg})$ and Pohang $(2384 \mu \mathrm{g} /$ kg) [41], Kathmandu (1172 $\mu \mathrm{g} / \mathrm{kg}$ ) [42], Cape Town $(4080 \pm 2640 \mu \mathrm{g} / \mathrm{kg})$ [43], and San Mateo Ixtatán (1401 $\mu \mathrm{g} /$ kg) [13]. But, PAHs concentrations in our study were above than those reported from Gwangju (51.2 $\mu \mathrm{g} / \mathrm{kg})$ [10] and Gyeonggi $(253 \mu \mathrm{g} / \mathrm{kg})$ [41].

\subsection{Toxicity of PAHs}

On the basis of cancer risk to humans, the Canadian Government established safe level of $\mathrm{BaP}_{\mathrm{TE}}$ $\left(600 \mu \mathrm{g} \mathrm{kg}^{-1}\right)$ for soils [28]. Observed $\sum \mathrm{BaP}_{\mathrm{TE}}$ for urban soils was comparatively above than rural soil. For urban soil, it had been ranged between $17.8-153.8 \mu \mathrm{g} \mathrm{kg}^{-1}$ (mean, $68.35 \mathrm{\mu g} \mathrm{kg}^{-1}$ ). While, for rural soils it ranged between $21.2-21.5 \mathrm{\mu g} \mathrm{kg}^{-1}$ (Fig. 2). The typical mean value of $\Sigma \mathrm{BaP}_{\mathrm{TE}}$ at S-1, S-2, S-3, S-4 and S-5 locations was $21.21 \mu \mathrm{g} \mathrm{kg}^{-1}, 88.12 \mu \mathrm{g} \mathrm{kg}^{-1}, 97.64 \mathrm{\mu g} \mathrm{kg}^{-1}$, $21.32 \mu \mathrm{g} \mathrm{kg}^{-1}$ and $80.59 \mu \mathrm{g} \mathrm{kg}^{-1}$, respectively (Table S4). However, $\mathrm{BaP}_{\mathrm{TE}}$ for $57 \mathrm{CPAH}$ at S-1, S-2, S-3, S-4 and S-5 locations was $20.7 \mu \mathrm{g} \mathrm{kg}^{-1}, 87.0 \mu \mathrm{g} \mathrm{kg}^{-1}, 95.7 \mu \mathrm{g} \mathrm{kg}$, $20.9 \mu \mathrm{g} \mathrm{kg}^{-1}$ and $79.4 \mu \mathrm{g} \mathrm{kg}^{-1}$, respectively. The mean value of 7CPAHs in urban and rural soils was $171 \pm 16 \mu \mathrm{g} \mathrm{kg}^{-1}$ and $80 \pm 2.89 \mu \mathrm{g} \mathrm{kg}^{-1}$, respectively, which accounted for $28.6 \%$ and $35.8 \%$, respectively to $\Sigma 16 \mathrm{PAHs}$. Whereas, their percent contribution to 516CPAHs at S-1, S-2, S-3, S-4 and S-5 was 26.5, 31.6, $28.6,35.8$ and 25.6 , respectively (Table S3). The 2-3ring PAHs show a negligible contribution $(0.7-1.2 \%)$ to $\mathrm{BaP}_{\mathrm{TE}}$. However, 5-ring PAHs and 6-ring PAHs were the main contributors to total $\mathrm{BaP}_{\mathrm{TE}}$, followed by 4-ring PAHs. The contribution of 5-ring and 6-ring PAHs accounted for $94.7 \%$ and $91.2 \%$ to $\Sigma \mathrm{BaP}_{\mathrm{TE}}$ for urban soils and rural soils, respectively. Results of $\mathrm{BaP}_{\mathrm{TE}}$, indicated that $\mathrm{DBA}$ and $\mathrm{BaP}$ including with other PAHs (BaA, BbF and $\mathrm{BkF}$ ) play a sustantial role in the toxicity potential of PAHs. However, observed $\mathrm{BaP}_{\mathrm{TE}}$ were lower than safe level [28], suggested low carcinogenic potential in soils. The observed values of $\mathrm{BaP}_{\mathrm{TE}}$ were less than those reported for soils from Orlando \& Tampa in USA (452 \& $802 \mu \mathrm{g} \mathrm{kg}^{-1}$ ) [36], Kolkata $\left(1129 \mathrm{\mu g} \mathrm{kg}^{-1}\right)$ [14], Dhanbad (120-720 $\left.\mathrm{g} \mathrm{kg}^{-1}\right)$ [44], and Delhi region (154-671 $\mathrm{\mu g} \mathrm{kg}^{-1}$ ) [20-22] in India. However, lower concentrations of $\mathrm{BaP}_{\mathrm{TE}}$ are reported for Wuhan $\left(34.55 \mu \mathrm{g} \mathrm{kg}^{-1}\right)$ [9], Tajikistan $\left(0.21-31.19 \mu \mathrm{g} \mathrm{kg}^{-1}\right)$ [45], and Rawalpindi (12.88 $\left.\mathrm{g} \mathrm{kg}^{-1}\right)$ [46].

\subsection{Possible source identification of PAHs}

\subsubsection{PAHs with different rings}

The 16 PAHs are often grouped according to the presence of aromatic rings as 2-3 rings, 4- rings, 5- rings and 6- rings PAHs. Occurrence of these groups of PAHs within the environment are indicative of their possible origin sources. The 2-3-rings PAHs were the dominant homolog, followed by 4-ring PAHs, and 5-ring to 6-ring PAHs at different locations (Table S3). The dominance of 2-3 ring and 4-ring PAHs indicated mixed pyrogenic sources. Local vehicular emissions may be the sources of 3- to 4- rings PAHs in rural area. These homologs can exist both within the vapor and particulate phase [22], and settle down in nearby areas. The concentration of 5-ring $\left(107 \pm 2.4 \mu \mathrm{g} \mathrm{kg}^{-1}\right)$ and 6-ring $\left(157 \pm 14 \mu \mathrm{g} \mathrm{kg}^{-1}\right)$ $\mathrm{PAH}$ s was comparatively higher at location S-3. Comparatively higher contribution of $2-3$ ring $\mathrm{PAHs}$ to $\sum \mathrm{PAHs}$ was 
Fig. 3 Molecular ratio of selected PAHs

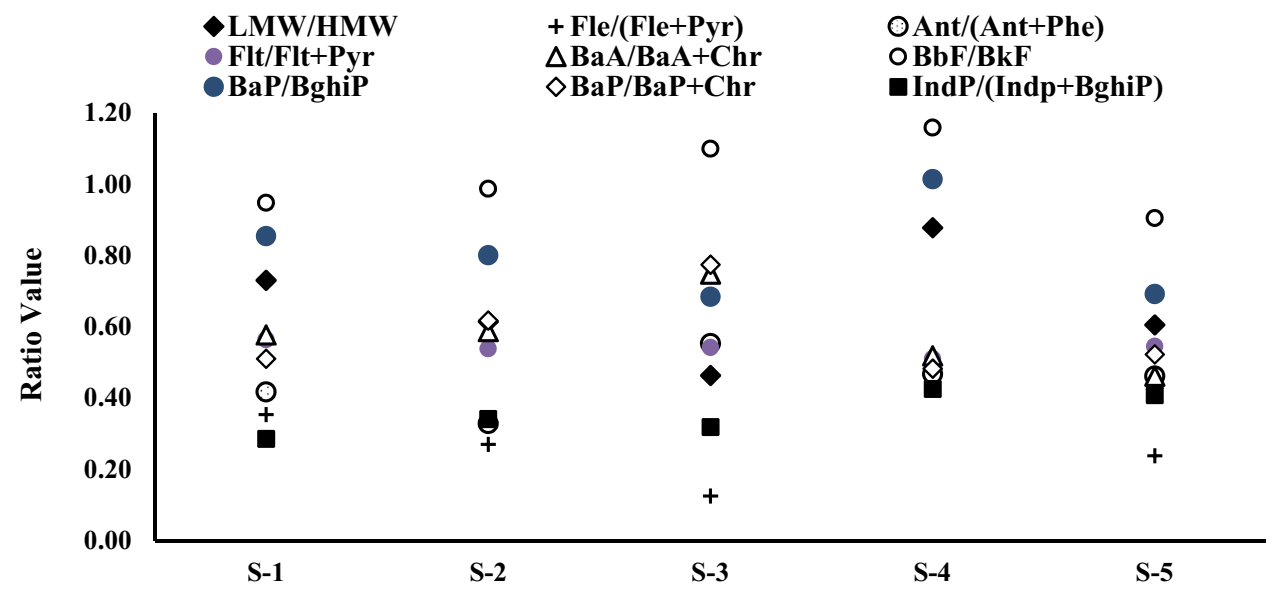

observed at rural site (46.7\%) than all urban sites (36.5\%). 4-ring PAHs were dominant at urban sites than rural sites, and their contribution was accounted for $35.2 \% 24.4 \%$ to $\Sigma$ PAHs, respectively. The contribution of 5-ring and 6-ring PAHs was between 12.9-17.6\% and 11.3-15.0\% to $\Sigma$ PAHs, respectively.

Further, different PAHs with their molecular weights are often related to various emission sources. For

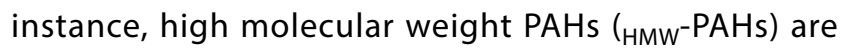
usually released from pyrogenic sources including coal combustion and vehicular emissions. While, low molec-

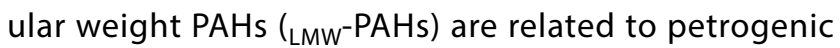
sources and combustion of woods, grass and industrial oil $[33,47,48]$. The typical concentration of $\Sigma_{\text {LMW }}-P A H s \&$ $\Sigma_{\text {HMW }}$-PAHs in urban and rural soils accounted for $35 \%$ \& $64 \%$, and $47 \%$ \& 53\%, respectively to $\Sigma 16 \mathrm{PAHs}$. Compara-

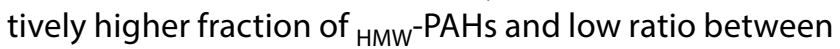
$\mathrm{LMW}^{-}$-PAHs and ${ }_{\mathrm{HMW}}$-PAHs (<1.0) (Fig. 3, Table S5), indicating pyrogenic processes as major sources of PAHs [41]. Various pyrogenic sources for air particles in Delhi are reported from vehicular emissions, construction activities, diesel engines, power plants, industries and biomass burning $[24,25]$.

\subsubsection{Diagnostic ratios of selected PAHs}

Molecular diagnostic ratios of selected $\mathrm{PAH}$ including ANT/(ANT + PHE), FLT/(FLT + PYR), BaA/(BaA + CHR), BbF/ $\mathrm{BkF}, \mathrm{BaP} / \mathrm{BghiP}, \mathrm{BaP} /(\mathrm{BaP}+\mathrm{Chr})$, and IndP/(IndP + BghiP) were used for identification of possible sources of PAHs $[33,47-53]$. The estimated values of selected ratio for this study was presented in Fig. 3, Table S5, which suggested mixed pyrogenic sources of PAHs. The ratio of $\mathrm{BaA} / \mathrm{Chr}$ in the present study was ranged between $0.44-0.78$ indicating recent deposition, also as transportation of fresh and older masses onto Delhi soils. It was reported that $\mathrm{BaA} / \mathrm{Chr}$ ratio $<0.40$ indicates the movement of older sources of $\mathrm{PAHs}$, while $>0.04$ ratio value indicates recent emissions and comparatively low photochemical degradation of PAHs [54]. Supported with these results, study suggested mixed pyrolytic sources. PAHs emissions from vehicles, diesel engines, coal, wood \& biomass combustions and gasoline have been reported in Delhi $[22,55]$. However, petrogenic sources could also be from accidental spills of petroleum products and automobile workshops.

\subsubsection{Pearson's coefficient of correlation}

Correlation analysis was performed for the idea that two or more PAHs could also be correlated to common source of origin. Relationships between individual PAH as Pearson's moment correlation coefficients were determined and presented in Table S6. Significant correlation (two tailed, $p<0.01, p<0.001$ ) between the ${ }_{\mathrm{LMw}}$-PAHs as well as $\mathrm{HMW}^{-\mathrm{PAHs}}$ was obtained during this study. A significantly strong correlation between ${ }_{L M W}$-PAHs like ANY, ANE, FLE, PHE, and ANT are often associated to biomass combustions at low temperature. Strong correlation between FLE, PHE, ANT, CHR and PYR suggested biomass combustions sources. A significant correlation among $\mathrm{FLT}, \mathrm{BbF}$, PYR, BaA, CHR, BkF, BaP, BghiP, DBA and IndP suggested emissions sources from high temperature combustion process like in vehicles, industries and coal combustion $[33,49,50]$. Stationary source emissions are related to correlations between $\mathrm{BaA}$ with $\mathrm{BaP}, \mathrm{BghiP}$ and IndP [55]. The presence of industrial and coal combustion emissions within the vicinity of the inhibited area has been attributed to stationary sources. These results demonstrated 
the mixed sources of PAHs in soils. The study concluded that pyrogenic sources like biomass and coal combustion and vehicular emissions could be the foremost significant sources of PAHs in the soils from Delhi. Various combustion processes are reported as the primary sources of PAHs in Delhi region $[20,55,56]$.

\subsection{Human health risk and environmental health hazard assessment}

\subsubsection{Human health risk}

Human health risk assessment was supported on assumption that humans could be exposed directly or indirectly to PAHs contaminated soil. Health risk to Humans as ILCR was based on the calculated daily intake of PAHs as LADD for human adults and youngsters. The recommended daily intake of BaP for human adult is $0.02 \mathrm{~g} \mathrm{~kg}^{-1} \mathrm{~d}^{-1}$ [57]. Various agencies have recommended acceptable ILCR of $10^{-6}$ [28] and $7.3 \times 10^{-3}$ [29]. Soil quality guidelines for direct contact $\left(\mathrm{SQG}_{\mathrm{DH}}\right)$ based on ILCR of $10^{-6}$ due to carcinogenic PAHs (BaA, BaP, BbF, BkF, BghiP, Chr, and IndP) were stipulated as $600 \mu \mathrm{g} \mathrm{kg}^{-1}$. Further, IACR of $\leq 1$ has been recommended as safe level for the protection of potable water $\left(\mathrm{SQG}_{\mathrm{PW}}\right)$ [28].

Observed LADD for adults and children are varied with respect to concentrations of PAHs at different sampling locations (Table 1). The daily intake of PAHs as LADD for human adults was ranged between $3.28 \times 10^{-8}-1.07 \times$ $10^{-7} \mathrm{mg} \mathrm{kg}^{-1} \mathrm{~d}^{-1}$, and for children it had been ranged between $1.22 \times 10^{-7}-5.04 \times 10^{-7} \mathrm{mg} \mathrm{kg}^{-1} \mathrm{~d}^{-1}$ (Fig. 4). Average LADD for human adults and children $\left(1.05 \times 10^{-7}\right.$ and $3.91 \times 10^{-7} \mathrm{mg} \mathrm{kg}^{-1} \mathrm{~d}^{-1}$ ) were higher at urban sites than rural site $\left(3.28 \times 10^{-8}\right.$ and $\left.1.22 \times 10^{-7} \mathrm{mg} \mathrm{kg}^{-1} \mathrm{~d}^{-1}\right)$, but were less than the recommended guidelines. Daily intake of $\Sigma_{\text {LMW }}$-PAHs $\left(2.64 \times 10^{-9} \mathrm{mg} \mathrm{kg}^{-1} \mathrm{~d}^{-1}\right)$ was less than the $\Sigma_{\text {HMW }}$-PAHs $\left(3.48 \times 10^{-7} \mathrm{mg} \mathrm{kg}^{-1} \mathrm{~d}^{-1}\right)$. Among HMW $^{-P A H s}$, the $\mathrm{BaP}$ (5-ring $\mathrm{PAH}$ ) and the DBA (6-ring PAHs) were the main contributor to $\mathrm{BaP}_{\mathrm{TE}}$, thus increasing the LADD (Table S7). The estimated ILCR at different locations was comparatively higher for youngsters than adults (Table 2). ILCR for adults varied between $4.47 \times 10^{-6}-4.49 \times 10^{-6}$, and for children it had been ranged between $1.66 \times 10^{-5}-7.64 \times 10^{-5}$. ILCR for human adults $\left(1.44 \times 10^{-5}\right)$ and children $\left(5.35 \times 10^{-5}\right)$ at urban locations was comparatively higher, than rural location (adult, $4.49 \times 10^{-6}$, and children, $1.67 \times 10^{-5}$ ), but within the acceptable guidelines. Among urban locations, ILCR for human adults and children lower at location S-1 $\left(4.47 \times 10^{-6} \& 1.66 \times 10^{-5}\right)$ than other locations (Fig. 4). Almost like LADD, majority of ILCR was

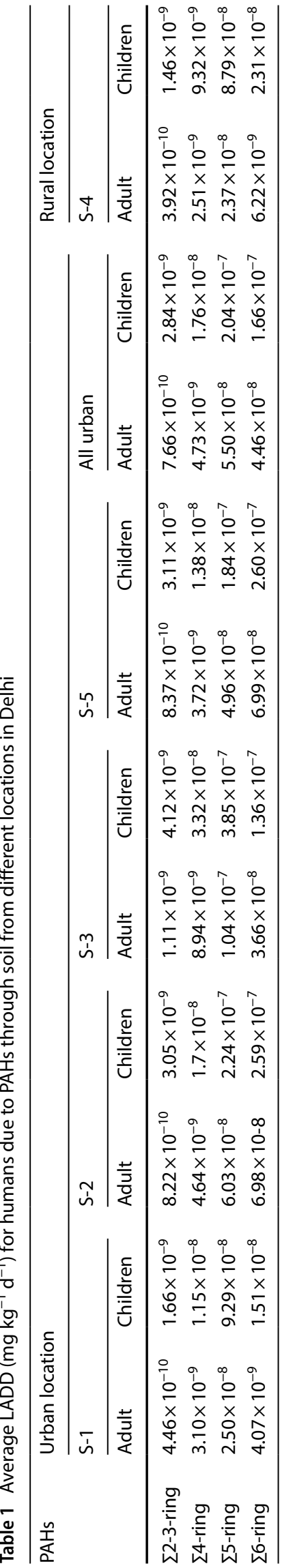

SN Applied Sciences A SPRINGER NATURE journal 
Fig. 4 Average LADD ( $\mathrm{mg} \mathrm{kg}^{-1}$ day $^{-1}$ ) and ILCR to humans due to exposure to $\Sigma 16 \mathrm{PAHs}$ through soil

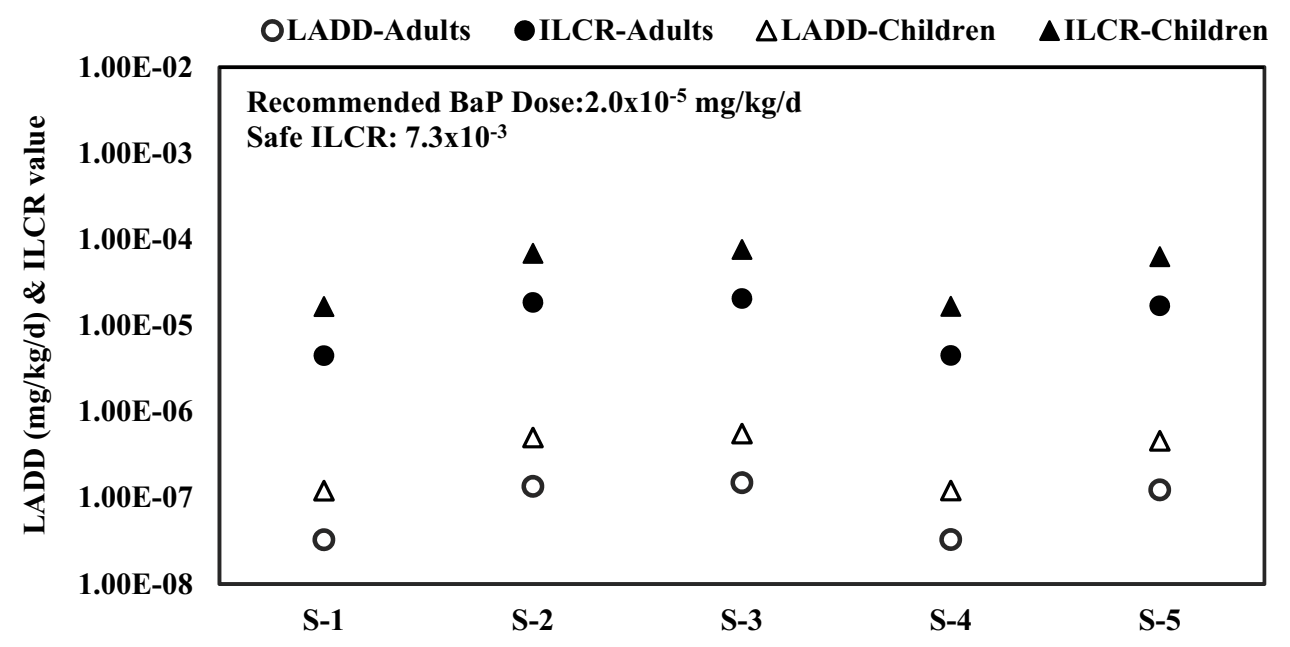

contributed by $\Sigma_{\mathrm{HMW}}$-PAHs $\left(4.76 \times 10^{-5}\right)$ compared with $\Sigma_{\text {LMW }}$-PAHs $\left(3.61 \times 10^{-7}\right)$. Higher TEF for BaP and DBA [27] has increased the $\Sigma \mathrm{BaP}_{\mathrm{TE}}(>93 \%)$ and ILCR.

The observed ILCR for humans due to PAHs during this study were comparable with ILCR reported for various Indian locations like Dhanbad (adults, $6.93 \times 10^{-5}$, children, $6.22 \times 10^{-5}$; adults, $1.82 \times 10^{-5}$, children, $1.85 \times 10^{-5}$; adults, $3.36 \times 10^{-6}-7.53 \times 10^{-6}$, children $2.65 \times 10^{-6}-8.19 \times 10^{-6}$ ) [14-16], Ghaziabad (adults $7.7 \times 10^{-5}$, children $4.5 \times 10^{-5}$ ) [18], Gwalior (adults, $6.4 \times 10^{-5}$, children, $2.4 \times 10^{-4}$ ) [19], Korba (adults, $6.7 \times 10^{-5}$, children, $3.5 \times 10^{-5}$ ) [58] and Kurukshetra (adults, $8.1 \times 10^{-6}$, children, $4.2 \times 10^{-5}$ ) [59]. ILCR was also comparable with reported for cities of other countries including Beijing, China (adults, $2.48 \times 10^{-6}-3.08 \times 10^{-6}$, children, $\left.1.56 \times 10^{-6}-2.69 \times 10^{-6}\right)$ [35], and USA $\left(6 \times 10^{-5}\right)$ [60]. But was less than Mashad, Iran (adults, $6.2 \times 10^{-4}$, children, $7 \times 10^{-4}$ ) [8], Kutahya, Turkey (adults, $5.71 \times 10^{-6}$ to $3.19 \times 10^{-4}$ ) [12], Guatemala (adults, $1.61 \times 10^{-4}$ ) [13], and higher than Yinma (children, $1.00 \times 10^{-6}$ to $1.18 \times 10^{-6}$, adults, $1.10 \times 10^{-6}$ to $4.22 \times 10^{-6}$ ) [6], Liaohe (children, $4.03 \times 10^{-8}$, adults, $1.14 \times 10^{-7}$ ) [7], Wuhan (adults $1.13 \times 10^{-8}$ to $3.54 \times 10^{-8}$, children $9.23 \times 10^{-7}$ to $9.51 \times 10^{-6}$ ) [9], Gwangju in South Korea (adults, $8.41 \times 10^{-6}$, children,
$3.61 \times 10^{-7}$ ) [10], and North-West China (adults, $1.19 \times 10^{-9}$ Children, $1.79 \times 10^{-9}$ ) [11].

The BaP TPE and IACR was ranged between 0.017-0.153 $\mathrm{mg} \mathrm{kg}^{-1}$ (mean, $0.061 \mathrm{mg} \mathrm{kg}^{-1}$ ) and 0.26-0.99 (mean, 0.55), respectively, and less than specified guidelines for $\mathrm{SQG}_{\mathrm{DH}}$ and $\mathrm{SQG}_{\mathrm{PW}}$. PAHs associated human health hazard in terms of BaP TPE and IACR was relatively low at S-1 and S-2 than other locations (Fig. 5).

\subsubsection{Environmental and human health hazard}

PAHs levels observed during this study were compared with specified SQGs for the protection of environmental and human health for the assessment of health hazard from non-carcinogenic effects of PAHs [28, 31]. It was found that the observed levels of ${ }^{2} 16 \mathrm{PAHs}$, LMW-PAHs, ${ }_{\mathrm{HMW}}{ }^{-\mathrm{PAH}} \mathrm{s}$, and individual compounds were less than recommended SQGs (Table S8), suggested low environmental and human health hazard. Further, $\mathrm{NCl}$ values (range, 0.02-0.19, mean 0.06) revealed that the pollution level due to PAHs was in safe category. Furthermore, as per classification of pollution level of PAHs in soils [61], soils in Delhi were found to be weakly polluted at S-1 and S-2 locations, 


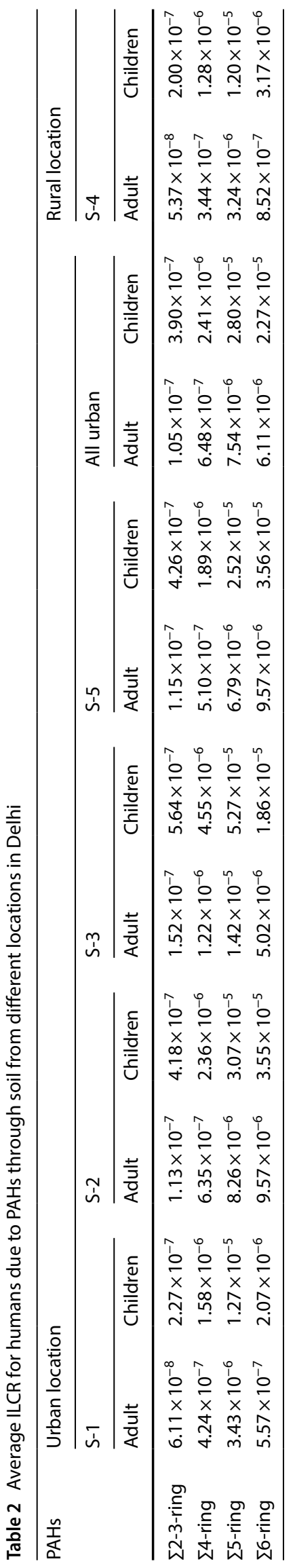

while S-3, S-4 and S-5 locations as moderately polluted soils with PAHs.

\section{Conclusions}

This study revealed that the levels of PAHs in soils from rural location were comparatively lower than the urban locations, and those were less than SQGs suggested low environmental health hazard. $\mathrm{NCl}$ and soil classification, suggested weekly polluted soils with $\mathrm{PAHs}$, but, categorized in safe category. The dominant $\mathrm{PAH}$ compounds in soils were FLT, PYR, NPT, PHE, ANY, ANE, ANT, BaP and BghiP, and their combined contribution accounted for $72 \%$ to $\Sigma 16 \mathrm{PAHs}$. Study indicated mixed pyrolytic sources from vehicular emissions from diesel engines; coal, wood $\&$ biomass combustions, and gasoline are the significant contributor of PAHs to soils in Delhi.

Daily intake of PAHs as LADD and subsequent ILCR for adults and children, varied location-wise with variable concentrations and the PAHs sources. $\Sigma_{\mathrm{HMW}}$-PAHs were the major contributor to total LADD and ILCR. However, LADD and ILCR were less than the guidelines. Observed values of $\mathrm{BaP}_{\mathrm{TE}}, \mathrm{BaP}$ TPE and IACR were also lower than guidelines indicated low health hazard due to carcinogenic effects of PAHs. 
Fig. 5 BaPTPE $\left(\mathrm{mg} \mathrm{kg}^{-1}\right)$ and IACR in urban and rural soils

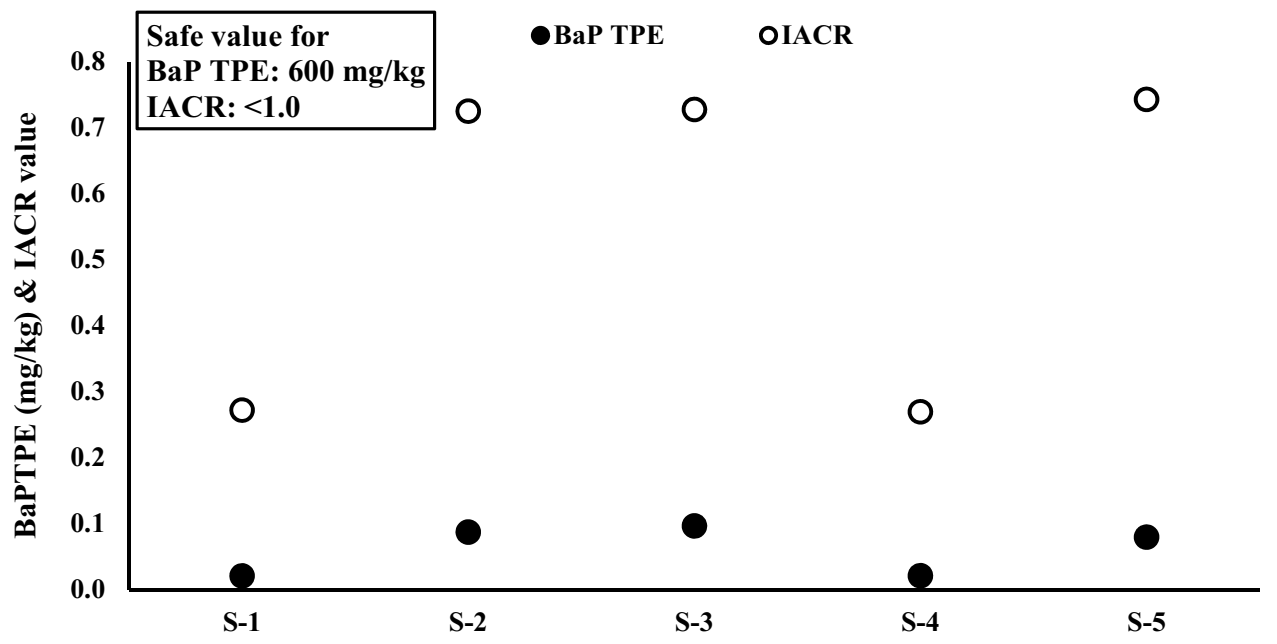

Acknowledgements The authors are grateful to competent authorities of Central Pollution Control Board for providing the necessary facilities to conduct study. DJ is thankful to authorities of CPCB for permission to conduct this study for the requirement for post graduate dissertations. The views expressed in this paper are those of authors and do not necessarily reflect the organization's.

\section{Compliance with ethical standards}

Conflict of interest All authors declare that they have no conflict of interest.

\section{References}

1. ATSDR (Agency for Toxic Substances and Disease Registry) (1995) Toxicological profile for polycyclic aromatic hydrocarbons (PAHs). US Department of Health and Human Services, Public Health Service. Atlanta, GA. http://www.atdsr.cdc.gov/toxpr o.les/phs69. Accessed 10 Jan 2020

2. U.S. EPA (United States Environmental Protection Agency) (2015) Appendix A to 40 CFR, Part 423-126 priority pollutants. https ://www.gpo.gov/fdsys/pkg/CFR-2018-title40-vol31/pdf/CFR2018-title40-vol31-part423-appA.pdf. Accessed 30 Jan 2020

3. EC (European Community) (2001) The list of priority substances in the field of water policy and amending directive, Council directive 2455/2001/ECC. Off J L331:1-5

4. IARC (International Agency for Research on Cancer) (2010) IARC Monographs on the evaluation of carcinogenic risks to humans. Vol. 92, Some Non-heterocyclic polycyclic aromatic hydrocarbons and some related exposures. Lyone, France, https://monog raphs.iarc.fr/monographs-available/. Accessed 10 Jan 2020

5. ATSDR (Agency for Toxic Substances and Disease Registry) (2005) Public Health Assessment Guidance Manual (2005 Update). http://www.atsdr.cdc.gov/hac/PHAManual/toc.html. Accessed 20 Jan 2020

6. Chen $\mathrm{Y}$, Zhang J, Zhang $\mathrm{F}$ et al (2018) Contamination and health risk assessment of PAHs in farmland soils of the Yinma River Basin, China. Ecotoxicol Environ Saf 156:383-390

7. Lang Y, Zhao H, Liu B, Zhu C (2018) The levels and potential carcinogenic risks of PAHs in Liaohe Estuarine Reed wetland soils. Arch Environ Contam Toxicol 74:452-460
8. Ali N, Farid M, Behnam K, Zahra S (2018) Pollution, source apportionment and health risk of potentially toxic elements (PTEs) and polycyclic aromatic hydrocarbons (PAHs) in urban street dust of Mashhad, the second largest city of Iran. J Geochem Explor 190:154-169

9. Gereslassie T, Workineh A, Liu X et al (2018) Occurrence and ecological and human health risk assessment of polycyclic aromatic hydrocarbons in soils from Wuhan, Central China. Int J Environ Res Public Health 15:2751. https://doi.org/10.3390/ ijerph15122751

10. Islam NM, Jo YT, Chung SY, Park JH (2018) Assessment of polycyclic aromatic hydrocarbons in school playground soils in urban Gwangju, South Korea. Arch Environ Contam Toxicol 74:431-441

11. Liu Y, Wu Y, Xia Y et al (2017) Aliphatic and polycyclic aromatic hydrocarbons (PAHs) in soils of the northwest Qinling Mountains: Patterns, potential risk and an appraisal of the $\mathrm{PAH}$ ratios to infer their source. J Environ Sci Health Pt A 52:320-332

12. Dumanoglu Y, Gaga EO, Gungormus E et al (2017) Spatial and seasonal variations, sources, air-soil exchange, and carcinogenic risk assessment for PAHs and PCBs in air and soil of Kutahya, Turkey, the province of thermal power plants. Sci Total Environ 580:920-935

13. Kasaraneni VK, Vinka OC (2016) Polycyclic aromatic hydrocarbon contamination in soils of San Mateo Ixtatán, Guatemala: occurrence, sources, and health risk assessment. J Environ Qual 45:1-9

14. Ghosh SP, Maiti SK (2019) Evaluation of PAHs concentration and cancer risk assessment on human health in a roadside soil: a case study. Human Ecol Risk Assess. https://doi. org/10.1080/10807039.2018.1551052

15. Tarafdar A, Sinha A (2018) Health risk assessment and source study of PAHs from roadside soil dust of a heavy mining area in India. Arch Environ Occup Health 74(5):252-262. https:// doi.org/10.1080/19338244.2018.1444575

16. Tarafdar A, Sinha A (2017) Estimation of decrease in cancer risk by biodegradation of PAHs content from an urban traffic soil. Environ Sci Pollut Res Int 24:10373-10380

17. Devi NL, Yadav IC, Qi Q et al (2016) Environmental carcinogenic polycyclic aromatic hydrocarbons in soil from Himalayas, India: implications for spatial distribution, sources apportionment and risk assessment. Chemosphere 144:493-502

18. Kumar B, Verma VK, Tyagi J et al (2015b) Health risk due to sixteen $\mathrm{PAHs}$ in residential street soils from industrial region, 
Ghaziabad, Uttar Pradesh, India. J Environ Protect Sustain Dev 1:101-106

19. Kumar B, Verma VK, Sharma CS, Akolkar AB (2015c) Estimation of toxicity equivalency and probabilistic health risk on lifetime daily intake of polycyclic aromatic hydrocarbons from urban residential soils. Human Ecol Risk Assess 21:434-444

20. Agarwal T, Khillare PS, Shridhar V, Ray S (2009) Pattern, sources and toxic potential of PAHs in the agricultural soils of Delhi, India. J Hazard Mater 163:1033-1039

21. Singh DP, Gadi R, Mandal TK (2012) Levels, sources, and toxic potential of polycyclic aromatic hydrocarbons in urban soil of Delhi, India. Human Ecol Risk Assess 18:393-411

22. Ray S, Khillare PS, Kim KH, Brown RJC (2012) Distribution, sources, and association of polycyclic aromatic hydrocarbons, black carbon, and total organic carbon in size-segregated soil samples along a background-urban-rural transect. Environ Eng Sci 29:1008-1019

23. DES (Directorate of Economics and Statistics) (2016) Statistical Abstract of Delhi, 2016. Government of National Capital Territory of Delhi, Delhi, India. http://des.delhigovt.nic.in/wps/wcm/ connect/DOIT_DES/des/home/. Accessed 30 Jan 2020

24. Hama SML, Kumar P, Harrison RM et al (2020) Four-year assessment of ambient particulate matter and trace gases in the DelhiNCR region of India. Sustain Cities Soc 54:102003

25. Sharma SK, Sharma A, Saxena M et al (2016) Chemical characterization and source apportionment of aerosol at an urban area of Central Delhi, India. Atmos Pollut Res 7:110-121

26. Kumar B, Goel G, Gaur R et al (2012) Distribution, composition profiles and source identification of polycyclic aromatic hydrocarbons in roadside soil of Delhi, India. J Environ Earth Sci 2:10-22

27. Tsai PJ, Shih TS, Chen HL et al (2004) Assessing and predicting the exposures of polycyclic aromatic hydrocarbons (PAHs) and their carcinogenic potencies from vehicle engine exhausts to highway toll station workers. Atmos Environ 38:333-343

28. CCME (Canadian Council of Ministers of the Environment) (2010) Canadian soil quality guidelines for the protection of environmental and human health: Carcinogenic and other PAHs. In: Canadian environmental quality guidelines, 1999, 200 Winnipeg, Canada http://www.ccme.ca

29. USEPA (United States Environmental Protection Agency) (2019) USEPA regional screening levels. https://www.epa.gov/risk/ regional-screening-levels-rsls. Accessed 28 Feb 2020

30. Narsinga Rao BS (2010) Nutrient requirement and safe dietary intake for Indians. Bull Nutr Found India 31:1-5

31. Buckman MF (2008) NOAA screening quick reference tables (SQuiRTs). NOAA OR\&R REPORT 08-1. Office of the Response and Restoration Division, National Oceanography and Atmospheric Administration, Seattle, WA, 34 pages

32. Sun Y, Sun G, Zhou Q et al (2012) Polycyclic aromatic hydrocarbon (PAH) contamination in the urban topsoils of Shenyang, China. Soil Sediment Contam Int J 21:901-917

33. Khalili NR, Scheff PA, Holsen TM (1995) PAH source fingerprints for coke ovens, diesel and gasoline engines, highway tunnels, and wood combustion emissions. Atmos Environ 29:533-542

34. Gupta H, Kumar R (2020) Distribution of selected polycyclic aromatic hydrocarbons in urban soils of Delhi, India. Environ Technol Innov 17:100500

35. Cao W, Yin L, Zhang D et al (2019) Contamination, sources, and health risks associated with soil PAHs in rebuilt land from a coking plant, Beijing, China. Int J Environ Res Public Health 16:670. https://doi.org/10.3390/ijerph16040670

36. Liu Y, Gao P, Su J, da Silva EB et al (2019) PAHs in urban soils of two Florida cities: background concentrations, distribution, and sources. Chemosphere 214:220-227
37. Kuang S, Su Y, Zhang J, Song Z et al (2018) Distribution and sources of polycyclic aromatic hydrocarbons in soils from Shengli Oil Field. China Soil Water Res 13(2):74-82

38. Wang L, Zhang S, Wang L, Zhang W, Shi X, Lu X, Li X, Li X (2018) Concentration and risk evaluation of polycyclic aromatic hydrocarbons in urban soil in the typical semi-arid city of Xi'an in Northwest China. Int J Environ Res Public Health 2018(15):607. https://doi.org/10.3390/ijerph15040607

39. Wu J, Li K, Ma D, Yu N, Chai C (2018) Contamination, source identification, and risk assessment of polycyclic aromatic hydrocarbons in agricultural soils around a typical coking plant in Shandong, China. Human Ecol Risk Assess 24(1):225-241

40. Yang J, Yu F, Yu Y, Zhang J, Wang R, Srinivasulu M, Vasenev VI (2016) Characterization, source apportionment, and risk assessment of polycyclic aromatic hydrocarbons in urban soil of Nanjing, China. J Soil Sediment 17(4):1-10. https://doi.org/10.1007/ s11368-016-1585-0

41. Kim L, Jeon H, Kim Y, Yang S et al (2019) Monitoring polycyclic aromatic hydrocarbon concentrations and distributions in rice paddy soils from Gyeonggi-do, Ulsan, and Pohang. Appl Biol Chem 62:18. https://doi.org/10.1186/s13765-019-0423-7

42. Pokhrel B, Gong P, Wang X, Chen M, Wang C, Gao S (2018) Distribution, sources, and air-soil exchange of OCPs, PCBs and PAHs in urban soils of Nepal. Chemosphere 200:532-541

43. Raissa AO, Wewers F, Ikhide PO, Farrar T, Giwa A-R (2017) Spatio-temporal distribution of polycyclic aromatic hydrocarbons in urban soils in Cape Town, South Africa. Int J Environ Res 11:189-196

44. Suman S, Sinha A, Tarafdar A (2016) Polycyclic aromatic hydrocarbons (PAHs) concentration levels, pattern, source identification and soil toxicity assessment in urban traffic soil of Dhanbad, India. Sci Total Environ 545-546:353-360

45. Zhao Z, Zeng H, Wu J, Zhang L (2017) Concentrations, sources and potential ecological risks of polycyclic aromatic hydrocarbons in soils from Tajikistan. Int. J. Environ Pollut 6:13-28

46. Saba B, Hashmi I, Ali Awan M et al (2012) Distribution, toxicity level, and concentration of polycyclic aromatic hydrocarbons (PAHs) in surface soil and groundwater of Rawalpindi, Pakistan. Desalination Water Treat 49:240-247

47. Marr LC, Kirchstetter TW, Harley RA (1999) Characterization of polycyclic aromatic hydrocarbons in motor vehicle fuels and exhaust emissions. Environ Sci Technol 33:3091-3099

48. Dickhut RM, Canuel EA, Gustafson KE et al (2000) Automotive sources of carcinogenic polycyclic aromatic hydrocarbons associated with particulate matter in the Chesapeake Bay Region. Environ Sci Technol 34:4635-4640

49. Chen YG, Sheng GY, Bi XH (2005) Emission factors for carbonaceous particles and polycyclic aromatic hydrocarbons from residential coal combustion in China. Environ Sci Technol 39:1861-1867

50. Wilcke W (2007) Global patterns of polycyclic aromatic hydrocarbons (PAHs) in soil. Geoderma 141:157-166

51. Simcik MF, Eisenreich SJ, Lioy PJ (1999) Source apportionment and source/sink relationship of PAHs in the coastal atmosphere of Chicago and Lake Michigan. Atmos Environ 33:5071-5079

52. Yunker MB, Macdonald RW, Vingarzan R et al (2002) PAHs in the Fraser River basin: a critical appraisal of PAH ratios as indicators of PAH source and composition. Org Geochem 33:489-515

53. Lee WJ, Wang YF, Lin TC et al (1995) PAH characteristics in the ambient air of traffic-source. Sci Total Environ 159:185-200

54. Kaur S, Senthilkumar K, Verma VK (2013) Preliminary analysis of polycyclic aromatic hydrocarbons in air particles $\left(\mathrm{PM}_{10}\right)$ in Amritsar, India: sources, apportionment, and possible risk implications to humans. Arch Environ Contam Toxicol 65:382-395 
55. Ray S, Khillare PS, Kim KH (2013) Profiles, carcinogenic potencies, sources and association of black carbon and polycyclic aromatic hydrocarbons in size-fractionated urban and forest soils of Delhi, India. Int J Environ Eng Manag 4:581-584

56. Hazarika N, Srivastava A (2016) Estimation of risk factor of elements and PAHs in size-differentiated particles in the National Capital Region of India. Air Qual Atmos Health 10(4). https://doi. org/10.1007/s11869-016-0438-8

57. Environment Agency (2002) Contaminants in soil: Benzo(a) Pyrene. Environment Agency, UK. http://www.iehconsulting. co.uk/IEH_Consulting/IEHCPubs/HumExpRiskAssess/CLR9.pdf. Accessed 15 Feb 2020

58. Kumar B, VermaVK KS, Sharma CS (2014) Polycyclic aromatic hydrocarbons in residential soils from an Indian city near power plants area and assessment of health risk for human population. Polycycl Aromat Compd 34:191-213
59. Kumar B, Verma VK, Kumar S, Sharma CS (2013) Probabilistic health risk assessment of polycyclic aromatic hydrocarbons and polychlorinated biphenyls in urban soils from a tropical city of India. J Environ Sci Health A 48:1253-1263

60. Williams ES, Mahler BJ, Metre PC (2013) Cancer risk from incidental ingestion exposures to PAHs associated with coal-tar-sealed pavement. Environ Sci Technol 47:1101-1109

61. Maliszewska-Kordybach B (1996) Polycyclic aromatic hydrocarbons in agricultural soils in Poland: preliminary proposals for criteria to evaluate the level of soil contamination. Appl Geochem 11:121-127

Publisher's Note Springer Nature remains neutral with regard to jurisdictional claims in published maps and institutional affiliations. 